\section{HIV and AIDS}

HIV and AIDS, KE Nye, JM Parkin. pp xi +88 , illustrated. Bios, Oxford, 1994. $£ 15.00$, paperback

HIV and AIDS provides a well-balanced comprehensive account covering pathogenesis, key clinical presentations and management, as well as a brief look at possible future novel therapeutic approaches including immunomodulation and vaccines.

The style of the book is lucid and written in such a way as to make a complex subject more easily understood. The diagrams and explanations are well produced and clear and readily facilitate understanding. The book is comfortable to read and in a book of its size the authors have struck a good balance between coverage, emphasis, and detail and have been able to maintain a consistent style throughout.

One of the great problems for authors when writing in such a dynamic and changing field as HIV and AIDS is mantaining currency of information. Despite this problem, the content appears very up-to-date.

Whilst in a book of this size it is not possible to cover subjects in any great depth, I consider that the book more than fulfils its intended role as a useful text for medical students and clinicians, especially those not regularly involved with the day-to-day management of AIDS patients, but who nevertheless require a sound working knowledge of this important disease. It should also be of value to general practitioners and to students and researchers in the life sciences. It deserves a place on the shelves of medical libraries.

At its price I consider it represents good value and I recommend it as a useful adjunct to the ever growing body of literature on this fascinating but tragic disease.

DJ TIMMINS

Department of Genitourinary Medicine, The Royal Liverpool University Hospital, Liverpool, UK

\section{Clinical chemistry}

Clinical chemistry in diagnosis and treatment, 6 edn, PD Mayne. pp 440, illustrated. Edward Arnold, London, 1994. f14.99, paperback

It is 20 years since I last read what was then known as Zilva and Pannall in great detail. The book has subsequently been through five editions and has acquired a new main author, Philip Mayne. The number of reprints and editions is testament to the success of this clearly written and concise textbook of clinical biochemistry, incorporating fundamental biochemical principles. I relished the opportunity of revisiting the book's sixth edition.

The original principles for the book have not altered with time and it remains a comprehensive and well-presented introduction to a difficult topic, as viewed by undergraduate students. The 25 chapters cover all the important aspects of clinical biochemistry from the kidney and renal calculi through to the biochemical effects of tumours and the procedure for examination of the cerebrospinal fluid. In addition, there are sections which review the important areas of drug monitoring, the clinician's contribution to valid results and requesting and interpreting results. I do not recall these latter sections from earlier editions although I suspect that they were there - teaching of biochemistry 20 years ago emphasised the biochemical pathways rather than their utility in clinical diagnosis and management. It is unfortunate that only a minority of medical students are inspired by chemical pathology at first introduction. One possible explanation is the way biochemistry is so often taught in the curriculum, apparently independent of the clinical process. This book must be commended for the way it attempts to bridge this gap: disease processes are given good mention in relation to every biochemical process. This would be strengthened if short case histories were included in the new edition rather than being divorced to a companion volume. I have very few criticisms of the book although I personally consider free thyroxine measurement has now superseded total thyroxine, and plasma ACTH measurements and MRI scanning have come of age (these being somewhat overlooked in the text). I agree with $\mathrm{Dr}$ Mayne's conjecture that reference ranges are not required in such a textbook but the inclusion rather than exclusion, as in the new edition, of further reading lists should be encouraged in these days of self-directed learning. In summary, I enjoyed this latest edition of an old friend and will continue to recommend it to undergraduate medical students. Moreover, it remains a valuable reference for postgraduate students, particularly when used as an adjunct to day-to-day clinical practice.

PETER KOPELMAN The London Hospital Medical College, London E1 2AD, UK

\section{Clinical chemistry}

A workbook of clinical chemistry, PD Mayne, AP Day. pp 196, illustrated. Edward Arnold, London, 1994. £10.99, paperback

This book is designed to partner Clinical chemistry in diagnosis and treatment by helping the student to interpret biochemical data in a clinical context and thereby emphasising the very clinical nature of chemical pathology. The book contains 15 sections: the first and the last sections, which cover interpretation of biochemical data and details of test protocols, are closely associated with the text of the parent book. The intervening sections are arranged to correspond with the appropriate chapters in Clinical chemistry and each section includes five genuine but anonymised case reports. The reader is invited to answer questions based on the given laboratory data about the first of each series of case reports before turning the page to read the authors' explanation. The remaining four reports provide a clinical scenario followed by an inter- pretation of the biochemical findings. Section 14 contains more orthodox data interpretation from the chemical pathologist's point of view with one-line case summaries and limited biochemical findings - the opposite page contains a succinct summary of the likely cause of the abnormality shown. I did wonder about the relevance and value of this section to an undergraduate student, given the cited objective to encourage him or her to consider biochemical findings within the entire clinical context. Overall the book does provide a useful adjunct to Clinical chemistry but should be seen very much as a revision aid rather than a book from which to acquire new knowledge. Moreover, I suspect the book may find its major readership in those studying for higher qualifications, as many undergraduates may find the case reports unnecessarily complicated.

PETER KOPELMAN

The London Hospital Medical College, London E1 2AD, UK

\section{Clinical genetics}

ABC of clinical genetics, 2nd edn, HM Kingston. pp 71, illustrated. British Medical Journal, London, 1994. $£ 13.95$, paperback

The second edition of $A B C$ of clinical genetics upholds the traditional high standard of this series. Although it is a slim A4 book it is packed tight with relevant facts. The general style and layout is recognisably similar to the first edition. Dr Kingston's style of writing is undoubtedly 'reader friendly' but the economy of text and the remarkably comprehensive coverage certainly demands the reader's concentration. It deals consecutively with the various aspects and the facts fed to the reader in an unremitting stream are placed in a context which gives a balanced coverage of the subject and builds it up in logical sequence for the relative newcomer.

The layout is also 'reader friendly'. The half-page column of print provides a format which is not overpowering and the rest of the page is occupied by numerous helpful illustrations and diagrams. These are, of necessity, individually quite small but they are entirely adequate for their purpose. The chapter layout has the effect that the general medical reader comes across aspects of genetics with which he/she will be to some extent clinically familiar, whereas the chapters on DNA and molecular genetics, which might be regarded as the basic medical science of genetics have been left to the end and are thus rendered more comprehensible to the non-specialist reader. This enhances rather than detracts from the book's presentation.

As well as a standard index there is very useful glossary of terms; a list of support groups which would be very useful to the practising clinician; a guide to further study which again will be of help to the practising clinician by concentrating what is likely to be of value to the non-specialist in the field.

This is a well designed and executed book which medical students, hospital staff, post- 
graduate examination candidates and general practitioners will find of immense value.

AW BLAIR

Paediatric Department, Victoria Hospital, Kirkcaldy, Fife KY2 5AH, UK

\section{Stress}

Stress survival guide, C Grainger. pp 50, illustrated. British Medical Journal, London, 1994. $£ 6.95$, paperback

This is a short book written in an informal style and obviously based on a relatively recent acquaintance with the life of junior hospital doctors. The material is presented in a non-technical and unsophisticated way, but obviously deliberately so. There is repetition of the difficulties doctors have in recognising stress in themselves and others, and in being sympathetic and supportive rather than the more typical response of discerning weakness. Institutional causes are also given appropriate recognition; long hours of work lack of peer and senior support, and relocation every six months precluding relationships which acknowledge weaknesses as well as strengths. Suggested strategies of coping emphasise acknowledgement of stress, a life away from work, seeking those with whom one can discuss problems, the need for self care (? self respect), and skills in delegation, time management, and problem solving.

Neither the diagnosis nor the suggested treatment is new. Despite the optimistic tone one is left, as is the author, with a quite disheartening feeling that there is unlikely to be any major reduction of the unreasonable demands on junior doctors by 'the system' or senior colleagues. One then wonders to whom this book should best be addressed. A junior doctor who buys it because of stress might find it describes the problem without providing sufficient relief. Perhaps it might more profitably be read by consultants and those responsible for undergraduate teaching who might feel the need to do more to make the role of the junior doctor an enjoyable educational experience.

J HIGGINS

Postgraduate Medical Dean's Office, Hamilton House, Pall Mall, Liverpool L3, UK

\section{Books received}

Acute medicine algorithms, $M$ Singer, AR Webb. pp vii +172 , illustrated. Oxford University Press, Oxford, 1994. paperback

Controversies in healthcare policies challenge to practice, $M$ Marinker, ed. pp 128. British Medical Journal, London, 1994. $£ 12.95$, paperback

Doctors, dilemmas, decisions, B Essex pp 301. British Medical Journal, London, 1994. £22.95, paperback

The healing arts, RS Downie, ed. pp 330, illustrated. Oxford University Press, Oxford, 1994. $£ 18.99$, hardback
Medicine prep manual, $\mathrm{K}$ George, ed. pp 574, illustrated. Kalasala, Kerala, India 1994. price not given, paperback

Motor development in children, $\mathrm{E}$ Fedrizzi, G Avanzini, P Crenna, eds. pp vi + 179, illustrated. J Libbey, London, 1994. $£ 32.00$, hardback

Obesity in Europe 93, H Ditschuneit, FA Gries, H Hauner, V Schusdziarra, JG Wechsler, eds. pp xi +535 , illustrated. J Libbey, London, 1994. $£ 40.00$, hardback

100 Short cases for the MRCP, 2 edn, K Gupta. pp xvii + 277. Chapman \& Hall, London, 1994. £12.99, paperback
Outcomes into clinical practice, $T$ Delamothe, ed. pp 164, illustrated. British Medical Journal, London, 1994. £17.95, paperback

Resumes and personal statements for health professionals, JW Tysinger. pp x +1192 , illustrated. Galen, Tucson, Arizona, USA, 1994. \$15.95, paperback

Vandals at the gates of medicine, MA Faria. pp xvii +403 , illustrated. Hacienda, Georgia, USA, 1994. \$41.95, hardback

Vertigo and dizziness, L Yardley. pp 163. Routledge, London, 1994. £11.99, paperback 